\title{
Hermenéutica analógica y formación. Hacia un nuevo modelo de comprensión lectora
}

\author{
Analogical hermeneutics and training. Towards a new model \\ of reading comprehension
}

\author{
EdUARdo Mancipe Flechas \\ Universidad de La Salle \\ Bogotá, Colombia
}

\begin{abstract}
RESUMEN: El presente artículo analiza el potencial que tiene la hermenéutica analógica para configurar un nuevo modelo de formación en comprensión lectora, que podría responder de manera más adecuada a las expectativas y metas propuestas por las diversas instituciones encargadas de formular e implementar la política relacionada con los planes de lectura y bibliotecas de los diferentes países de la región. Para tal fin, se realiza una breve descripción del contexto iberoamericano y se analizan los alcances y límites de algunos modelos ya existentes que son reinterpretados a la luz de esta nueva mirada hermenéutica, de modo tal que se establecen algunos elementos de diferenciación e interrelación entre sus procesos de interpretación y comprensión, desde un abordaje interdisciplinar que hace confluir la filosofía, la psicología, la sociología y la pedagogía y que finalmente enuncia una propuesta que se desglosa en siete tesis.
\end{abstract}

AвSTRACT: This article analyzes the potential of analogical hermeneutics to configure a new training model for reading comprehension, able to respond with more adequacy to the goals set by the various institutions responsible for the designing of policies regarding reading plans and libraries in different countries of the region. To achieve this, a brief description of the Latinamerican context is given, in adittion to an analysis and reinterpretation of the scope and limits of certain existing models in light of the hermeneutical perspective proposed by Mauricio Beuchot. In doing so, we point out some differences and interrelations between those models and analogical hermeneutics in order to obtain an interdisciplinary approach that brings together philosophy, psychology, sociology and pedagogy. Finally, this leads to the development of a proposal broken down into seven theses.

PALABRAS ClAVE: hermenéutica analógica, formación lectora, modelos de comprensión lectora, estudios sobre lectura, interpretación de textos.

KEY WORDS: Analogical hermeneutics, reading training, reading comprehension models, studies on reading, text interpretation.

RECIBIDO: 20 de julio de 2014 • ACEPTADO: 10 de diciembre de 2014 



\author{
EdUARdo Mancipe Flechas \\ Universidad de La Salle \\ Bogotá, Colombia
}

\title{
Hermenéutica analógica y formación. Hacia un nuevo modelo de comprensión lectora ${ }^{1}$
}

\section{Antecedentes}

Este trabajo emerge de la complejidad que caracteriza aproximarse interdisciplinarmente al problema de la comprensión lectora de textos enmarcados en el área de humanidades, que considero una cuestión de carácter poliédrico, en el sentido de establecer la necesidad de abordarlo desde diversas disciplinas, entre otras: la filosofía, la psicología, la sociología y la pedagogía, y en las que es posible aplicar la hermenéutica analógica como modelo de interpretación.

Para tal fin, he estructurado este texto en cuatro partes. En la primera, se trata de mostrar, desde su contexto social, la necesidad de abordar el problema de la comprensión lectora en un ámbito como el de las bibliotecas públicas rurales y la posibilidad de proponer un modelo analógico para este fenómeno. En la segunda parte, se busca diferenciar y relacionar la interpretación y la comprensión desde la perspectiva de la hermenéutica analógica. En la tercera, se pretende

1 Este texto es resultado de la estancia de investigación de estudios del doctorado en Ciencias Sociales y Humanas de la Pontificia Universidad Javeriana de BogotáColombia, que se llevó a cabo en el Seminario de Hermenéutica del IIFL de la UNAM, bajo la dirección del doctor Mauricio Beuchot. Deseo agradecer al doctor Beuchot su magistral, constante y generosa orientación en el desarrollo de este trabajo. 
hacer ver cómo la hermenéutica analógica aporta a un abordaje interdisciplinar de la comprensión lectora de textos. Finalmente, en la cuarta parte se pondrán a consideración como horizontes de acción, siete tesis y una propuesta de articulación interdisciplinar para un modelo analógico de comprensión lectora.

\section{Génesis de un problema}

En una de las ponencias presentadas en junio de 2010, durante el II Congreso Nacional de Bibliotecas Públicas en Colombia, Luis Eduardo Ruiz (2010) compartió con el público asistente la reflexión que sobre la biblioteca viva hiciera Manuel Pérez, un habitante de San Basilio de Palenque: ${ }^{2}$

Nosotros y nosotras hemos contado con una biblioteca viva, como son nuestros abuelos y abuelas que han servido para que hoy en día nosotros y nosotras tengamos esa memoria viva, ese conocimiento de la información ancestral por medio de la transmisión oral. Pero creemos que es importante tener un medio también de transmisión escrita. ¿Por qué escrita? porque nosotros sabemos que cuando la información se escribe perdura en el tiempo y ahorita estamos teniendo una escasez de abuelos y abuelas [...] Esos abuelos y abuelas que tradicionalmente nos contaban nuestra historia están dejando de existir, entonces sería importante guardar esa información que tenemos para que las generaciones venideras cuenten con la herramienta para informarse de nuestra historia local, de nuestra historia negra, porque así creemos y queremos nosotros que se mantenga: como una historia negra. Sería importante tener información de medicina tradicional la que escribimos nosotros, la información de los músicos, de la religiosidad, de los cuentos, mitos y leyendas, los escritores negros... nuestra forma propia, nuestra forma rupia de producir, de la interacción con la naturaleza y todo lo que tiene que ver con nuestra idiosincrasia. [...] Así para que nuestra forma madre de hablar, nuestra lengua vernácula, esté también allí con los libros y diccionarios que ya se han escrito.

Esta bella narración deja entrever, entre otros aspectos: que desde una perspectiva de análisis reflexivo y comunicativo la doxa es uno

2 Es un corregimiento del municipio de Mahates, en el departamento de Bolívar, ubicado en la Costa Caribe colombiana. 
de los caminos de comprensión para abordar cualquier fenómeno; que la interpretación de los textos ${ }^{3}$ se mueve en tensiones como naturaleza/cultura, tradición/innovación, individuo/comunidad/sociedad, episteme/doxa, objetividad/subjetividad, subjetividad/intersubjetividad, instituciones/ciudadanos, entre otras, que han de analizarse desde el horizonte de la cotidianidad y la significación experiencial, pero teniendo siempre presente la relación de proporción que guardan entre sí. Así mismo, puede identificarse una serie de textos y contextos, que se enmarcan en lo que Freire ha llamado el acto de leer, que conducen a proponer nuevas condiciones del saber y formas emergentes de oralidad y escritura que estén relacionadas e impliquen cambios en la sensibilidad y la sociabilidad humana.

Un análisis de las acciones institucionales en esta línea, muestra que la lectura - al menos en principio - ha sido uno de los temas prioritarios en la agenda de las políticas públicas de los países iberoamericanos (especialmente en la última década). En la VI Conferencia Iberoamericana de Cultura (celebrada en Santo Domingo, República Dominicana, en octubre de 2002), se encomendó a la Organización de Estados Iberoamericanos (OEI) y al Centro Regional para el Fomento del Libro en América Latina y el Caribe (CERLALC) adelantar un Plan que posibilitara la articulación de las diversas acciones que se vienen desarrollando en la región, e identificara algunos de sus ejes comunes. Al asumir dicho compromiso, el CERLALC desarrolló un estudio en el que muestra que los planes nacionales de lectura en tanto sus concepciones, propósitos y metas, permiten identificar ocho líneas de acción: el fortalecimiento de las bibliotecas públicas, el fortalecimiento de la escuela, la conquista de nuevos espacios de lectura, la formación de mediadores, el garantizar la accesibilidad al libro, la generación de conciencia sobre el valor social del libro y la lectura, el fortalecimiento de los planes de lectura con la realización de estudios e investigaciones, y por último la divulgación de los planes, su ejecución y resultados (Peña e Isaza 2005: 166).

3 El texto es de varias clases. Ricoeur ha insistido en el paso de la expresión "texto" al ámbito de lo escrito, del diálogo y de la acción significativa (Beuchot 2009a: 14). 
Llama la atención en este estudio, que si bien todos los países analizados, sin excepción, consideran la formación de mediadores ${ }^{4}$ como una de sus acciones principales, sin embargo al momento de revisar los proyectos en marcha se perciben muy pocas acciones en esta dirección. Para el caso de Colombia, el Plan Nacional de Lectura y Bibliotecas (PNLB) en el 2005 evidenciaba un proceso "formativo" en el que a cada municipio se le asignaba un tutor para que trabajara con sus bibliotecarios durante un año, la capacitación se impartió a través de una modalidad semipresencial, y su contenido se centró en tres módulos: la formación de adultos lectores, la promoción de la lectura y el diseño de proyectos de promoción de lectura (Peña e Isaza 2005: 175). En el 2010, la actualización formativa que se ofreció a los bibliotecarios se enfocó en la realización de talleres regionales y de diplomados, impartidos por programas de Bibliotecología con una intensidad horaria presencial de 120 horas.

En cuanto al perfil de los bibliotecarios, en la red de bibliotecas municipales, sólo $1.05 \%$ son profesionales, $11 \%$ tienen una formación técnica y $87.5 \%$ son bachilleres (Rodríguez 2007: 15). La causa de estos indicadores se centra principalmente en la baja remuneración de los bibliotecarios municipales. Sus funciones implican el desarrollo de una serie de habilidades que van desde tener un nivel de lectura crítico, hasta ser capaces de desarrollar actividades de promoción lectora..$^{5}$ A esto se suma la diversidad de campos en los

4 Se considera mediadores a los maestros en ejercicio, maestros en formación, bibliotecarios públicos y escolares, equipos técnicos encargados de los planes y promotores de lectura. El presente texto se enfoca en los bibliotecarios públicos de zonas rurales.

5 Robledo explica cómo en la medida en que las características poblacionales se complejizan, el promotor de lectura debe tener la capacidad de : “ $a$ ) diseñar y planear un programa integral de promoción de lectura, con diferentes actividades; $b$ ) realizar un diagnóstico participativo con las poblaciones con las que va a desarrollar la acción de promoción-diagnóstico, tanto de sus condiciones económicas, sociales y culturales, como de sus necesidades de información, sus intereses y gusto; $c$ ) tener suficiente conocimiento de los materiales de lectura que le permita orientar la selección de acuerdo con la población y con la actividad a desarrollar; $d$ ) diseñar indicadores de evaluación que permitan medir, los procesos, y el impacto de su intervención; e) desarrollar directamente con los grupos las actividades de animación que permita a los lectores cuestionar los textos, interrogarlos y compartir las miradas sobre los mismos; $f$ ) tener la capacidad de escuchar al otro, de indagar sobre 
que puede desempeñarse profesionalmente un bibliotecólogo y el escaso número de programas de formación, haciendo que sólo $9 \%$ de sus egresados trabaje en Bibliotecas Públicas, concentrando su presencia en las cinco ciudades más importantes del país.

Este panorama refleja una serie de situaciones problemáticas:

a) La capacitación esporádica en modo alguno implica un proceso formativo, aún más habría que analizar los alcances de lo que significaría la formación en una institución como la Biblioteca Pública, que según se observa estaría más en el marco de la educación no formal que de la formal.

b) Se da por sentado que los bibliotecarios deben tener un nivel crítico de lectura. ¿Qué significa esto? ¿Cuáles son los modelos y posicionamientos que se asumen?

c) La condición multicultural, las tradiciones y comunidades a las que se pertenece, ¿cómo se articulan con esta condición crítica?

d) A la gradación de los niveles de lectura subyace un fenómeno transversal que es el de la comprensión e interpretación de textos, y las relaciones que existen entre los elementos del acto hermenéutico: texto, autor, lector y sus contextos.

e) ¿Qué niveles de complejidad expresa el fenómeno de comprensión lectora?

f) ¿Qué elementos deberían articularse para configurar un modelo de formación en comprensión lectora destinado a mediadores, como los bibliotecarios rurales, que esté ubicado en el ámbito de la educación no formal?

Resulta conveniente, como una primera aproximación, acudir a la comprensión crítica que ofrece Freire en torno al acto de leer. Él considera que:

leer no consiste solamente en decodificar la palabra o el lenguaje escrito; antes bien, es un acto precedido por (y entrelazado con) el conocimiento de la realidad. El lenguaje y la realidad están interco-

sus necesidades, sus intereses, sus gustos y sus maneras de apropiarse de los textos que lee" (Robledo 2010: 37). 
nectados dinámicamente. La comprensión que se alcanza a través de la lectura crítica de un texto implica percibir la relación que existe entre el texto y el contexto (Freire y Macedo 1989: 51).

En esta primera aproximación pueden identificarse, en el orden de la comprensión lectora, cuatro factores: los textos, los contextos, las subjetividades y las intersubjetividades, que interactúan con una tradición de conocimientos y saberes - desarrollada en comunidades a través de prácticas concretas - , como elementos vitales dentro de un proceso de formación, y que implican además como ruta de análisis el reconocimiento de la analogicidad, la reflexividad, la dialogicidad y la transformación.

Lo anterior es mostrado con mayor fuerza por Freire al afirmar que:

la lectura de la realidad siempre precede a la lectura de la palabra, así como la lectura de la palabra implica una continua lectura de la realidad, $[\ldots]$ este movimiento de la palabra a la realidad está siempre presente; incluso la palabra hablada fluye de la lectura de la realidad. Sin embargo, en cierta forma, podemos ir más allá y decir que la lectura de la palabra no está únicamente precedida por la lectura de la realidad, sino también por una cierta forma de escribirla o de reescribirla, es decir, de transformarla por medio de un trabajo consciente y práctico (Freire y Macedo 1989: 56).

Respecto al texto y el contexto y su relación con lo subjetivo e intersubjetivo confluyen diversos análisis: de carácter psicológico (en tanto proceso reflexivo y cognitivo de las relaciones del texto con la tradición, que implica un conocimiento y saber subjetivo); sociológico (en tanto la existencia de relaciones sociales en torno al texto y el desarrollo de una intersubjetividad); pedagógico (en tanto refiere a un proceso formativo permanente), y filosófico (en tanto requiere posicionamientos ontológicos y epistemológicos que a su vez implican un paradigma y una pragmática propios).

Una mirada epistemológica del fenómeno de la comprensión lectora que pretenda una comprensión no solamente subjetiva, sino intersubjetiva, con miras a desarrollar un proceso formativo, requiere desvelar los elementos imprescindibles para que pueda ser calificado como tal y mostrar qué relación se establece entre ellos (Melich 
1994: 52). Ahora bien, ¿cuáles son los aspectos sobre los que va a desarrollarse este proceso de comprensión interdisciplinar? Marciales (2003), a partir del modelo propuesto por Santiuste (2001), realiza un giro de la comprensión lectora que va de la filosofía a la psicología desde una perspectiva cognitiva-constructivista. Identifica que las creencias, estrategias e inferencias son elementos constitutivos de dicho fenómeno y ofrece además una taxonomía caracterizadora. Uno de los aportes centrales de esta propuesta es abordar la comprensión lectora como formación, para lo cual considera necesario:

que se logre una relación íntima entre el texto y la subjetividad, relación que puede ser pensada como experiencia. Con frecuencia el lector se mantiene como espectador, externo al texto sin transformarse. Concebir la lectura como formación supone romper la frontera entre lo que sabemos y lo que somos, entre lo que pasa y podemos conocer, y lo que nos pasa y podemos atribuir sentido con relación a nosotros mismos. Lo anterior implica pensar la lectura como una relación de producción de sentido. La formación implica necesariamente nuestra capacidad de escucha; aquí lo importante es que la relación no sea de apropiación sino de escucha. El saber, de esta manera, no queda fuera de nosotros, sino que adquiere sentido en la medida en que se integra a una subjetividad que se encuentra con otra subjetividad que la reta, la desestabiliza y la forma (Marciales 2003: 103).

Dado el nivel de comprensión desarrollado desde esta perspectiva, podrían retomarse las mismas categorías de análisis (creencias, estrategias e inferencias), inmersas en el orden de la subjetividad, y ampliarlas al orden de la intersubjetividad, asumiendo que el giro comunicacional deriva en lo sociológico, al incorporar las representaciones sociales, discursos y prácticas como elementos emergentes de lo comunicativo; descentrando el enfoque del constructivismo, para trasladarlo al orden de lo hermenéutico-analógico, puesto que considera que en los procesos de comprensión lectora converge no solamente la construcción sino también el descubrimiento.

En síntesis, se pretende analizar desde la hermenéutica analógica algunas de las relaciones que confluyen en torno al fenómeno de la comprensión lectora, entre la psicología - creencias, inferencias y estrategias - y la sociología - representaciones, discursos y prác- 
ticas - , con miras a configurar cooperativamente un modelo comprensivo de formación para los bibliotecarios rurales colombianos, que identifique contenidos, estrategias de formación y criterios de evaluación.

En relación con esta cuestión, se parte de las siguientes premisas básicas:

a) Las humanidades resultan insustituibles para alcanzar la interpretación crítica de la sociedad actual, la revitalización de la cultura, la reflexión sobre las grandes cuestiones personales y sociales y el ascenso del nivel de creatividad (Llano 1999: 168173). De allí la conveniencia de enfocar el fenómeno de la comprensión lectora en los textos enmarcados en esta área.

b) La capacidad de desarrollar el pensamiento crítico, de fomentar la comprensión de una variedad de experiencias humanas y de fortalecer el ejercicio de la ciudadanía dentro del marco de una democracia, está vinculada al cultivo de las humanidades, que actualmente padece un estado de crisis dentro del proceso formativo de las instituciones de educación superior (Nussbaum 2010) y podría cultivarse a través de otras instituciones como las bibliotecas públicas, orientadas por las dimensiones, aportaciones y estrategias de desarrollo ofrecidas por el aprendizaje permanente. ${ }^{6}$

c) La hermenéutica analógica se ha revelado singularmente apta para el diálogo entre diversas disciplinas científicas, lo que ha contribuido significativamente al desarrollo de un pensar multidisciplinar que encierra una potencia para abordajes de carácter interdisciplinar ${ }^{7}$ más amplios. Este modelo de interpretación retoma la phrónesis como herramienta analógica que junta porciones y las proporciona, las organiza y ordena; pues su estructura mixta hace que aunque sea teórica pueda verse sobre la práctica

6 Más adelante se tratará brevemente lo que se entiende por aprendizaje permanente y cómo a partir de allí podría comprenderse una formación permanente.

7 Basta con evidenciar la aplicación de la hermenéutica analógica no solamente en el ámbito de la filosofía, sino del derecho, la sociología, la pedagogía, la educación, la literatura, el arte, la historia, la psicología, la linguiística, la filología, entre otras. 
(Beuchot 2007: 100). Se centra en la analogía como modo de pensamiento que busca salvaguardar las diferencias en el margen de cierta unidad, y cuyo carácter relacional y ordenador pretende estructurar las cosas por sus semejanzas y diferencias, y por los grados de éstas últimas, ayudando a distinguir para poder unir armónicamente (Beuchot 2011b: 149).

d) Dado el carácter interdisciplinar de la hermenéutica analógica y por la complejidad del problema de la comprensión lectora, es factible articular la filosofía, la psicología, la sociología y la pedagogía.

\section{Interpretación y comprensión}

Toda hermenéutica demanda un equilibrio entre dos operaciones básicas: interpretación y comprensión. Interpretar significa enfrentarse con una estructura de sentido: descomponer lo ya constituido para descubrir su unidad interna. La interpretación es una tarea procesual que transcurre y se da en el tiempo, en tanto que la comprensión - dado su carácter teleológico-, pareciera no exigir tiempo alguno. La comprensión de suyo es institución de sentido. Éste - el sentido- es como un eidos, se realiza en la continua tensión entre lo uno y lo múltiple, entre el todo y la parte, de lo que necesita tiempo para ser. Sólo una interpretación proporcional genera la comprensión del sentido. El campo paradigmático en el que se ofrece esta operación de interpretación/comprensión es el texto.

Ahora bien, como afirma E. Coreth (1972), la interpretación se encuentra situada histórica y comunitariamente. El lector llega al texto con sus propios intereses, conocimientos previos, etc. Se sitúa en una tradición y desde ella accede al texto, evidenciando una pre-comprensión que va cambiando a medida que se desarrolla el proceso de interpretación. Lo que se conoce del texto después de ser leído y comprendido se convierte en pre-comprensión para una segunda lectura. Dicho proceso puede repetirse dependiendo de la riqueza del texto y de la capacidad personal del lector, lo cual denota que la comprensión tiene una estructura en espiral, que manifiesta un movimiento en donde 
la lectura de las partes de un texto ilumina la comprensión del todo así como la visión del todo contribuye a que se conozcan mejor las partes. Así, el lector entra en un texto con su mundo, su horizonte, el cual condiciona su comprensión particular del texto. A su vez, el texto amplía el horizonte del lector, obligándole a revisar su punto de partida. De este modo se esboza un nuevo proyecto de sentido que es contrastado por la lectura del texto, en donde las preguntas, respuestas y reacciones comunican toda su riqueza, lo cual expresa de algún modo el carácter dialógico de la comprensión. La comprensión además implica e incluye la explicación: estos son dos momentos relativos de un proceso más complejo, el de la interpretación. La explicación es una mediación necesaria para alcanzar una mejor comprensión. Para Ricoeur, "explicar es desentrañar la estructura, es decir, las relaciones internas de dependencia que constituyen lo estático del texto; interpretar es tomar el camino de pensamiento abierto por el texto, meterse en camino hacia el horizonte del texto" (2002: 155).

La tarea hermenéutica en la comprensión e interpretación no puede prescindir de la verdad. En palabras de Beuchot, "el texto exige cierta verdad como correspondencia para tener alguna pretensión de verdad. Pero esta verdad, un tanto parcial, se abriga en otra más radical y originaria, la del descubrimiento, desencubrimiento o desvelamiento, que la abarca y la explica" (2011a: 51). La verdad como apertura de mundo multívoco, que es expresión de diversos modos de ser, demanda una analogicidad que permita a la hermenéutica desplazar la relación de las interpretaciones y los hechos, a la donación del mundo como horizonte de sentido más originario, abriéndose así a la acción (Beuchot 2011a: 45-46).

Son numerosas las publicaciones que abordan el objeto de estudio de la hermenéutica analógica, y expresan cómo su carácter relacional de proporcionalidad y atribución evita la pretensión de alcanzar un significado claro y distinto, así como la ambigüedad de un significado confuso y oscuro. Este posicionamiento demanda en primer lugar una capacidad de distinción que es expresión de la naturaleza misma de la analogía, donde la primacía de la diferencia permite establecer, por sus contextos concretos, en qué aspectos se relacionan dos contrarios.

Lo anterior se observa con mayor claridad en los elementos cons- 
titutivos de la hermenéutica analógica: su estructura dinámica enuncia cómo confluyen la totalidad de un texto y los fragmentos del mismo; el carácter veritativo que le es explícito hace manifiesta la relación de los fragmentos, como correspondencia de los enunciados, y del todo, como coherencia de los mismos; concilia sentido y referencia; equilibra el sentido literal y el alegórico; reúne el describir y el valorar, el interpretar y el transformar, el decir y el mostrar, estableciendo como instrumento principal la distinción, y por tanto el diálogo, y ofreciendo criterios que pongan límites al campo de las interpretaciones (Beuchot 2010b: 80-83).

Una de las cuestiones que conlleva a reflexionar en torno a la articulación de la hermenéutica analógica y la fenomenología realista es qué tipo de teoría de la verdad está asociada a los conceptos, los juicios y las representaciones. Si bien se han ofrecido varias teorías al respecto (Conesa y Nubiola 1999: 144-161), me remitiré al análisis que hacen Inciarte y Llano (2007: 176) de la teoría de la verdad como adecuación y de la teoría de la verdad como coherencia, donde abordan de manera explícita su relación con el concepto, el juicio y la representación.

En primer lugar, la teoría de la verdad como adecuación es simplemente verdadera, sólo verdadera, está fundada en la inmediatez de la simple aprehensión, en la abstracción, que trabaja siempre con conceptos, “(...) lo que en el concepto se hace presente al entendimiento no es el objeto en su facticidad individual, sino el objeto de su esencia universal. [...] En el concepto, la mente discierne la esencia de la carne y la carne, es decir abstrae" (Llano 1997: 78). En segundo lugar, la teoría de la verdad como coherencia se funda en la mediatez, trabaja con los juicios y nunca es sólo verdadera, esto se deriva del hecho de que en el juicio hay una distinción entre sujeto y predicado, que hace que la falsedad sea posible (Inciarte y Llano 2007: 308). Ahora bien, Juan de Santo Tomás señala que "representar no es otra cosa que hacer al objeto conocido presente a la potencia y unido a ella en su ser cognoscible" (citado por Llano 1997: 77-78). Sin embargo, de la representación, en tanto permanece en el campo de la mera conciencia, no se puede reivindicar la cuestión de la verdad: lo verdadero y lo falso todavía no tienen sentido, puesto 
que para ello se requiere de conceptos que puedan combinarse (Inciarte y Llano 2007: 311).

De este análisis devienen de modo implícito dos tipos de relaciones, ambas vinculadas con teorías de la verdad: una de orden ontológico y otra de carácter epistemológico. El fenómeno de la comprensión lectora de textos no puede ser abordado únicamente desde lo representacional, sino que ha de tener como puntos de referencia el signo formal (los conceptos) y el signo lingüístico (instrumental) vinculado con los juicios; todo ello sustentado en una "metafísica mínima", que retomando las críticas de tan variados orígenes articule de modo proporcional y atributivo el concepto, el juicio y la representación, en el proceso de interpretación de textos que conlleva como fin teleológico la comprensión. Así, la hermenéutica percibe la necesidad de una ontología. En palabras de Beuchot:

el texto, al ser interpretado, requiere esclarecer su significado. Y el significado tiene dos caras, una de sentido y otra de referencia. La parte de sentido parece ser la propiamente hermenéutica, mientras que la parte referencial se muestra como la más ontológica. Al menos es la que señala o apunta hacia la realidad, por lo que requiere el instrumento conceptual para atisbar esa realidad que compete a los significados contenidos en los textos. A su aspecto referencial (2010a: 73).

\section{Visión de la interdisciplinariedad en la hermenéutica analógica}

Es conveniente ahora mostrar en qué radica la potencialidad que tiene este modelo de interpretación para abordar problemas de carácter interdisciplinar. Para tal fin se verá la gran afinidad que existe entre la visión de interdisciplinariedad de Evandro Agazzi (2002) y lo que podría llamarse la perspectiva analógica de lo interdisciplinario que se halla implícita en el abordaje que hace Beuchot de la cuestión del multiculturalismo y el interculturalismo (2010b: 63-74; 2009b), en donde se propone comprender cada disciplina como una cultura académica. ${ }^{8}$

8 Beuchot plantea una noción de cultura que no sea "puramente iluminista (o positivista, o cientificista, o univocista) ni puramente romántica (o relativista, o equivo- 
Beuchot ha expresado recientemente (2011a: 127-128) que él y Agazzi tuvieron como maestro en Friburgo a I. M. Bochenski, pensador polaco de gran relevancia por sus estudios de lógica - destaca su dedicación a la analogía-, así como por sus desarrollos del pensamiento griego y medieval. Al analizar la obra Filosofía de la naturaleza. Ciencia y cosmología, de Agazzi (2000), el pensador mexicano expresa cómo en el campo del conocimiento se ha necesitado con urgencia de un realismo científico ${ }^{9}$ que sepa articular ciencia y filosofía de la naturaleza, sin dejar de lado que una reflexión metafísica sobre la realidad natural no solamente es válida sino necesaria, puesto que es una clara manifestación del uso de una hermenéutica intermedia y mediadora entre el sentido y la referencia; es decir, al privilegiar el sentido, no anula ni excluye la referencia, sino que hace uso proporcional de ésta (Beuchot 2010a: 73). Es consciente de que "la ontología actual no puede ponerse aparte de la hermenéutica, sino ir con ella; es más, tiene que aprender de ella, construirse con la ayuda de ella" (Beuchot 2010a: 61).

Así, un realismo analógico de diferenciación de las ciencias ayuda a comprender cómo a éstas "no se las puede obligar, como quiso el positivismo, al modelo matematicista, ni se las puede dejar al acaso, como recientemente ha querido la posmodernidad, como rechazo al cientificismo de la modernidad" (Beuchot 2011a: 132). Además, la resistencia tajante a una reflexión ontológica ha conllevado a que las ciencias busquen sus referentes no en el sentido de su ser mismo, sino en la utilidad de su(s) método(s) y lógica(s), lo cual ha radicalizado sus posicionamientos unívocos o equívocos y reducido la reflexión filosófica al orden epistemológico.

Agazzi, en una primera caracterización de las disciplinas científicas (sean ciencias naturales o humanas), reconoce cómo en gran medida sus objetos de estudio constituyen realidades poliédricas, complejas y unitarias, cuyo abordaje:

cista), sino analógica, esto es, una que sepa armonizar la parte de racionalidad que hay en el hombre, con la parte de irracionalidad que también hay en él; una que sea capaz de salvaguardar las diferencias culturales sin perder la capacidad de reducirlas a cierta unidad, esto es de rescatar de lo particular aquellas regularidades que indican la presencia de algo universal, para así no perder ciertos universales de la convivencia, indicadores de una naturaleza humana que subyace a sus manifestaciones" (2009b: 23). 
se caracteriza por considerar el mundo de las "cosas" desde un único punto de vista particular, concentrando su enfoque sobre unos pocos "atributos" de las cosas y dejando fuera de su campo de investigación todos los demás (propiedades y relaciones de cada cosa). Por consiguiente, los conceptos que expresan dichos atributos y los predicados que traducen estos conceptos a un determinado lenguaje son también especializados, así como los procedimientos operativos que permiten controlar directamente la validez de las proposiciones de una determinada disciplina. Éstos constituyen una parte muy importante de la metodología de cada ciencia; la otra consiste en la determinación de los procedimientos lógicos que se utilizan para organizar el conocimiento, para establecer indirectamente la validez de proposiciones que no se pueden averiguar directamente, para ofrecer explicaciones y construir teorías (2002: 244-245).

Según lo anterior, en primer lugar, la ciencia es una actividad humana dirigida hacia unos objetivos determinados, donde se encuentran relacionadas íntimamente la teoría y la praxis. En segundo lugar, para conseguir esos objetivos, se utilizan métodos específicos, que son como una especie de corte de la realidad, realizado por cada ciencia, que define una cierta perspectiva y constituye su ámbito propio. Esto significa que el objeto de las disciplinas científicas no son las "cosas" en un sentido ordinario, puesto que una misma cosa se puede convertir en objeto de diferentes disciplinas, dependiendo del punto de vista que se adopte. ${ }^{10} \mathrm{Y}$ en tercer lugar, al aplicar esos métodos obtenemos unos resultados concretos, expresados en las construcciones científicas, que ordinariamente son un conjunto de proposiciones, conceptos, modelos y teorías, enmarcados en lógicas concretas.

En esta línea, resulta conveniente enunciar algunos enfoques disciplinares del fenómeno de la lectura. La psicología se ocupa de describir y explicar los elementos constitutivos que subyacen a la habilidad para comprender textos y el proceso de adquisición de di-

10 Es interesante recordar la perspectiva escolástica clásica, según la cual las ciencias se clasifican según sus objetos, distinguiendo dos tipos de ellos a los que se denomina objeto material y objeto formal. El primero es el tipo de seres que son estudiados por una ciencia; el segundo, es el punto de vista bajo el cual se estudia. Para el caso de la hermenéutica, el objeto material es el texto - en sus diferentes clases - y el punto de vista es la textualidad que hay que decodificar y contextuar (Beuchot 2009a: 14-15). 
cha habilidad, ${ }^{11}$ como es el caso del análisis de creencias, estrategias e inferencias relacionadas con la comprensión lectora. La sociología estudia la lectura en tanto sus prácticas sociales, los modos como se ha realizado, las maneras como se ha asumido desde la oralidad, la lectura silenciosa y en voz alta, individual o grupal, que inciden en las representaciones y discursos sociales. La pedagogía se enfoca en el papel formativo de la lectura o en la configuración de modelos de comprensión lectora. Sin contar con todas las perspectivas que pudiesen enunciarse en el ámbito de las humanidades, desde la literatura, la antropología, la historia y el derecho.

Es importante anotar que dentro de una misma disciplina académica $^{12}$ existe un conflicto de interpretaciones. Se evidencia, al menos, que, por un lado se tiene la interpretación personal de la misma, a la luz del horizonte de sentido que se va dando en cada individuo dentro de la apropiación de su cultura disciplinar; y por otro, se tiene la interpretación de esta última, en tanto comunidad académica que interpreta y que por ende tiene un ámbito más amplio y abarcador, cuyo horizonte de sentido se ha ido constituyendo internamente como ámbito cultural, de ideas, prácticas y valores (Beuchot 2010b: 68). Esto demanda:

una fusión de horizontes entre el horizonte individual y el horizonte común para que puedan convivir y sobrellevarse, e incluso es la manera en que se amplía y se promueve el horizonte comunitario por parte de los individuos. [...] [La] fusión de horizontes, es decir, su encuentro y su enriquecimiento se da cuando se identifican entre ellas una diferencia y la integran (llegando incluso a cambiar ideas y valores), aquí el diálogo entre dos hermenéuticas también tiene que resaltar las diferencias; esto es, identificar diferencias para integrar en la semejanza (Beuchot 2010b: 69).

El conflicto de horizontes puede superarse mediante la resolución de la semejanza, en la que nos comparamos con los otros e inten-

11 Abordada hasta el momento desde perspectivas cognitivas y/o constructivistas.

12 Las disciplinas académicas, entendidas como culturas, se organizan en función de determinadas tareas intelectuales y prácticas discursivas (Becher 2001). Según Elmborg (2008:109), es importante tener en cuenta que las comunidades disciplinares tienen unas características estructurales y unos estilos de comunicación específicos, que reflejan una comprensión de sus estilos disciplinares. 
tamos ponernos en su lugar; es decir, apropiarnos de sus propios términos, conceptos, teorías, lógicas y metodologías. Mas, como se ha dicho, esta operación nunca es completa; sin embargo, puede ser suficiente. Cuando el individuo de una cultura disciplinar concreta se compara con los demás e intenta ponerse en su lugar, apropiándose de sus términos, hace uso de la semejanza como argumento analógico $^{13}$ que conduce a aceptar o rechazar paradigmas inmersos en el marco de una comunidad o de una cultura. Esta sería una de las razones para repensar las humanidades a la luz de la hermenéutica analógica, como nuevo modelo interpretativo que ocupe un lugar relevante en la cartografía epistemológica de las ciencias sociales, para aquellos investigadores que pretenden comprensiones de la realidad social a la luz de una ontología y epistemología realistas.

La presencia de un problema complejo ${ }^{14}$ - como el que ha tratado de esbozarse en la comprensión lectora- demanda el uso de múltiples abordajes, que resultan comunicables gracias a una forma interrelacional que permite configurar varias perspectivas disciplinares en un programa de solución para dicho problema. Ésta es en esencia la motivación principal de la interdisciplinariedad, que no puede pensarse como contraposición a la especialización, sino como el proceso de armonización de diversas disciplinas para encontrar la comprensión y solución de un problema. Para ello, requiere de una

13 Es por ello que Beuchot afirma que: "El único medio que tenemos de cribar la objetividad alcanzable y evitar lo más que se pueda la mera subjetividad es la intersubjetividad en el diálogo y la discusión con los demás de la misma comunidad o con los pertenecientes a otras comunidades" (2009a: 51). Y además indica que el uso de la semejanza en la hermenéutica es "un intento de ampliar el margen de interpretaciones válidas de un texto sin perder los límites; de abrir la verdad textual, esto es, la de las lecturas posibles [de los horizontes de sentido] sin que se pierda la posibilidad de que haya una jerarquía de acercamientos a una verdad delimitada o delimitable" (1999: 12).

14 Para E. Morin, "La reforma necesaria del pensamiento es aquella que genera un pensamiento del contexto y de lo complejo. El pensamiento contextual busca siempre la relación de inseparabilidad y las inter-retroacciones entre cualquier fenómeno y su contexto. [...] El pensamiento complejo requiere de un pensamiento que capte las relaciones, interrelaciones, las implicaciones mutuas, los fenómenos multidimensionales, realidades que son simultáneamente solidarias y conflictivas [...] que respete la diversidad, al mismo tiempo que la unidad, un pensamiento organizador que concibe la relación recíproca entre todas las partes" (2005: 23). 
visión que tenga en cuenta las diferencias y comprenda además las razones y el sentido de estar juntas y relacionadas.

El desafío de un análisis interdisciplinar se centra en dos aspectos: el primero consiste en partir de las diferentes disciplinas, respetando la especificidad de sus conceptos, métodos y lógicas; el segundo, en impedir que todo ello se constituya en un obstáculo para la comunicación, propendiendo por una actitud de comprensión de la diversidad de sentidos de los conceptos y de los diversos tipos de racionalidad que le son inherentes. ${ }^{15}$ Es aquí en donde la hermenéutica analógica resultará "proporcionalidad de los significados y de las interpretaciones, [...] según la proporción que toca a cada una de acuerdo a su intencionalidad y a su contexto" (Beuchot 2009a: 112).

Un proyecto de investigación interdisciplinar emerge de un problema de comprensión de una realidad compleja, ${ }^{16}$ que implica la sutileza en la interpretación, vista ésta como un encontrar diversos sentidos cuando parecía haber sólo uno (Beuchot 2009a: 13-14), que al aplicarse en la interdisciplinariedad deviene en: delimitar de la manera más precisa el problema; determinar los elementos del problema que requieren ser abordados por disciplinas específicas que ofrezcan un mejor análisis de éste; hacer explícitas las diferencias que caracterizan la perspectiva de dichas disciplinas; establecer los diversos criterios aceptados por cada disciplina para recolectar información; explicitar el contexto teórico que cada disciplina acepta para el análisis de información; analizar el significado de los concep-

15 En este mismo sentido, Japiassu (1976) caracteriza a la interdisciplinariedad por la intensidad de intercambios entre especialistas y el grado de integración real de las disciplinas en torno a un mismo proyecto de investigación, que exige un proceso constante de interpenetración en el que las disciplinas se fecunden recíprocamente cada vez más. Para ello, es imprescindible la complementariedad de los métodos, los conceptos, las estructuras y los axiomas sobre los que se fundan las diversas prácticas pedagógicas de las disciplinas científicas. Así, afirma que "desde un punto de vista integrador, la interdisciplinariedad requiere un equilibrio entre la amplitud, la profundidad y la síntesis. La amplitud asegura una extensa base de conocimiento e información. La profundidad asegura el requisito de conocimiento e información disciplinar y/o interdisciplinar, para la tarea por realizar. La síntesis asegura el proceso integrador" (Japiassu 1976: 65-66).

16 Realidad en su sentido más amplio. 
tos utilizados en cada disciplina, estableciendo relaciones con su contexto teórico y con el proceso de recolección y análisis de información; comprender que cada disciplina utiliza procedimientos lógicos que, sin dejar de ser rigurosos, no coinciden con el tipo de "lógica" adoptado por otras disciplinas. Desde esta perspectiva, la hermenéutica analógica resulta sumamente útil porque:

no se centra en la sola diferencia sino balanceándola con la identidad; pero acepta que la diferencia predomine, sólo que, para no caer en el equivocismo, pide de esa diferencia equilibrada o catalizada con la tensión hacia la identidad, en lo cual consiste la semejanza o analogía; por eso una hermenéutica analógica ayudará a privilegiar esas diferencias, pero sin perder la capacidad de verlas al trasluz de algo que, a partir de las semejanzas las unifique y vea lo universal, llámese condición humana, naturaleza humana o como sea (Beuchot 2010b: 70-71).

A nivel de los modelos de comprensión lectora, salvo el de Marciales (2003) - enunciado anteriormente - , todos se han construido desde los elementos disciplinares ofrecidos por la psicología y la educación. El estudio de este fenómeno ha derivado en un número significativo de perspectivas y modelos que han intentado explicarla. En cuanto a paradigmas se refiere, los que han tenido mayor incidencia en la investigación y enseñanza de la comprensión lectora son el positivista y el constructivista ${ }^{17}$ (Coll 2001), lo que deja entrever la necesidad de un desarrollo analógico. En relación con los enfoques, los más representativos desde la perspectiva psicológica son el

17 Existen diversos constructivismos: constructivismo cognitivo, constructivismo de orientación sociocultural y constructivismo vinculado al construccionismo social. 


\section{conductista ${ }^{18}$ el cognitivo, ${ }^{19}$ el interaccional ${ }^{20} \mathrm{y}$ el constructivista ${ }^{21}$}

18 Según Goodman (1984), esta perspectiva de base positivista concibe la lectura como "Tecnología de la lectura", centrando su atención en el lector principiante. $\mathrm{Su}$ base instrumental y metodológica es de carácter cuantitativo y experimental; supone que el texto tiene un solo significado y que el proceso lector se reduce a una decodificación, en donde quien lee es un simple receptor que asume una posición pasiva en términos de interpretación del texto. El proceso de evaluación de las habilidades lectoras se enfoca en la aplicación de test. Esta óptica no tiene en cuenta variables personales, como los conocimientos previos, la motivación o intencionalidad lectora, ni el significado que construye el lector; tampoco variables contextuales, como el contexto sociocultural del lector, las diversas funciones que adquiere la lectura de acuerdo con el entorno social o las experiencias de lectura compartidas con otras personas.

19 Este enfoque centra sus estudios en la percepción, los procesos de memoria, el aprendizaje y el razonamiento lógico; concibe el significado del texto como resultante de las aportaciones del escritor y sostiene que el producto de la lectura debe ser confrontado con la intención comunicativa del mismo. Para que la persona logre comprender el contenido de un texto, la información debe procesarse en distintos niveles (palabra, oración, texto), destacando la automatización en el reconocimiento de palabras, lo cual libera recursos cognitivos que contribuyen a la interpretación. Dentro de los aportes centrales de esta perspectiva se encuentra la diferenciación entre leer y comprender.

20 Sus estudios parten del supuesto de que la comprensión está dirigida simultáneamente por los datos del texto y por el conocimiento preexistente en el lector. Considera que el significado está parcialmente determinado por el texto en sí, y que por ello es necesario que el lector aporte sus propios conocimientos para llevar a cabo un proceso constructivo e inferencial, en el que formula y comprueba hipótesis acerca de lo que trata el texto, para así lograr comprenderlo. Dado lo anterior, resulta comprensible que las perspectivas interaccionales hayan aceptado la noción de esquema como principio explicativo (Alonso y Mateos 1985). El significado no reside en las palabras, ni en las frases, ni en los párrafos, ni siquiera en el texto considerado globalmente, sino que reside en el lector, que activamente construye o representa la información del texto acomodándola a su conocimiento del mundo y a sus propósitos de comprensión en un momento dado. De este modo, la construcción de significado es el resultado de la interacción entre el texto, los esquemas de conocimiento y el contexto de varios tipos (lingüístico, situacional, actitudinal, de requerimientos de la tarea, etcétera) (De Vega 1994).

21 Concibe la lectura como una construcción social en la que el lector juega un papel activo durante el proceso de comprensión, pero además otorga un mayor énfasis a los aspectos socioculturales. En el proceso de comprensión del texto, la presente perspectiva le otorga un papel fundamental al signo. Durante la lectura, el lector utiliza los signos con la finalidad de dar sentido a la configuración del texto; en este proceso se considera que el lector compone mentalmente "otro" texto (Smagorinsky 2001). Desde este enfoque, todo acto de lectura también implica al contexto, que se define como la relación existente entre las personas, sus herramientas de mediación y el entorno, que incluye niveles de objetivos superpuestos, valores, discursos, he- 
(Solé 1992; Solé y Teberosky 2001); en cada uno subyace una concepción diferente del lector, del texto y del contexto implicados.

En cuanto a los modelos de comprensión lectora, ${ }^{22}$ en su gran mayoría han sido construidos en las últimas cuatro décadas. Por el grado de difusión, influencia, investigación que han generado, comprensibilidad y posibilidades de aplicación, han sobresalido los siguientes: a) modelos de comprensión desarrollados por Kintsch y sus colaboradores (1980, 1988, 1998); b) el modelo de construcción de estructuras de Gernsbacher (1990, 1991, 1996, 1997); c) los modelos Reader y el modelo de comprensión basado en la capacidad de la memoria de trabajo de Just y Carpenter (1980, 1992) y Just, Carpenter y Wooley (1982); d) el modelo del experimentador inmerso y el modelo de indexación de eventos de Zwaan y colaboradores $(1995,1998,2004) .{ }^{23}$ En general, sus análisis se han centrado en los siguientes aspectos: los relacionados con el texto, enfocándose en los tipos de textos cuya comprensión explica el modelo; los relacionados con el lector, que abordan los conocimientos del lector, sus objetivos y metas, sus factores afectivos y de motivación y su capacidad de operación; los niveles de procesamiento de la representación del texto, en cuanto a su formato de la representación, sus niveles de representación y la capacidad de recordar el texto; la capacidad de explicación de las diferencias individuales,

rramientas y otros aspectos de la vida social (Cole 1996). El contexto de lectura invoca convenciones particulares que influyen en el sentido que se atribuye al texto que se lee. Dichas convenciones son fruto de determinadas tradiciones que tienen sus propias maneras de comprender, utilizar y referirse a los signos. Los textos, como configuración de signos, se elaboran porque existe una intencionalidad de quien los escribe, y de esta manera el autor utiliza el texto como instrumento para comunicar, en el sentido de influir en el contexto.

22 Para tener un panorama general de los modelos existentes resulta imprescindible consultar el enjundioso estudio que realiza Juan Carlos Ripoll (2010), en su tesis doctoral de la Universidad de Navarra.

23 Sólo para tener una idea de otros modelos, Ripoll (2010: 139-140) refiere la existencia de estos otros modelos que describe brevemente: a) Modelo de la dependencia conceptual de Schank (1972); b) Modelo de Laberge y Samuels (1974); c) Modelo de procesos de Kieras (1981); d) Teoría de los modelos mentales (Garnham 1981; Johnson-Laird 1983; Garnham y Oakhill 1992; Garnham y Oakhill, 1996; e) Modelo de la Gestalt de historias de St. John (1992); f) Modelo constructivista de Graesser, Singer y Trabasso (1994); g) Modelo del paisaje de van den Broek, Young y Tzeng (1999). 
en el desarrollo de la comprensión lectora, y entre aquellos que son considerados como "lectores competentes"; la relación con diversos métodos que mejoran la comprensión lectora; y la capacidad crítica a otros modelos.

Estos modelos, dada la multiplicidad de procesos que intervienen, conciben la comprensión lectora como un fenómeno complejo cuyo fin es configurar la representación mental de un texto, en el que interactúan las ideas que se extraen del texto y los conocimientos del lector. Dada la polisemia de las palabras, manifiestan la necesidad de elegir el significado más adecuado a cada contexto, para lo cual el lector ha de "desactivar" los significados que no se adecuen al contexto en el que se encuentra la palabra. Asimismo, expresan que muchas de las ideas del texto no están plasmadas de manera explícita, por lo cual deben ser inferidas. Consideran que los recursos mentales con los que cuenta el lector son limitados, y que el carácter secuencial de la lectura hace que los textos se procesen en pequeños ciclos, de tal modo que la comprensión discurra simultáneamente con la lectura del texto. Finalmente, articulan el procesamiento por ciclos con la atención consciente del lector, quien se concentra en la parte del texto que lee en el momento, haciendo que la representación de lo ya leído permanezca en un estado de latencia que pueda ser recuperada cuando sea necesario.

Retomando la dinámica que conduce a la interdisciplinariedad: una vez desarrollado el proceso de distinción y contraste disciplinar, es posible iniciar un diálogo, donde cada disciplina ve el problema desde su propia perspectiva. Esta es una etapa multidisciplinar avanzada que ha puesto las condiciones para comparar diferentes discursos, válidos, pero parciales. El tránsito a una perspectiva interdisciplinar se desarrolla al iniciar una reflexión epistemológica conducente a percibir una exigencia de unidad, que lleve a considerar cada discurso no como un discurso cerrado y autónomo, sino como una voz específica que cumple un papel armónico dentro de un concierto. Esto significa tomar conciencia de la parcialidad de las diversas perspectivas disciplinares en relación con el "punto de vista de la totalidad", que, a su vez, requiere de cierta capacidad hermenéutica para "interpretar" dentro del propio lenguaje los discursos de otras 
disciplinas, manteniendo, en lo posible, su sentido y configurando una actitud que permita el intercambio continuo de discursos que desarrollen un mejor nivel de comprensión; que evite al mismo tiempo la univocidad disciplinar, al pretender que dicha visión abarca la totalidad del problema, y la equivocidad en el sentido de "creer" que hablaban el mismo discurso, mientras que en realidad usaban las mismas expresiones con sentidos diferentes. Lo analógico emerge cuando se reformula el propio discurso a partir del discurso disciplinar de los otros, sin pretender que dicha reformulación corresponda a una traducción perfecta. En palabras de Beuchot:

Es importante resaltar el hecho de que nuestra autocomprensión se enriquecerá al trasluz de la heterocomprensión o comprensión de los otros, tanto de la que ellos tienen de sí mismos, como de la que nosotros tenemos de ellos, incluso nos moverá a transformarnos a nosotros mismos $[\ldots]$ una hermenéutica analógica podrá ayudarnos, en este terreno común que crea, a comprendernos mejor a la luz de nuestra comprensión de los otros y de la comprensión que los otros tienen de nosotros, de nuestra cultura [disciplinar], y así poder criticar y modificar cosas de nuestra propia cultura. Curiosamente se ha vuelto una interpretación transformadora, una hermenéutica transubstanciadora. Incide en lo real, nos ayuda a comprendernos y transformarnos, al igual que ayuda a los otros a comprenderse y transformarse (2010b: 71-72).

El camino ya descrito conduce a la continua tensión con la que prosigue el trabajo interdisciplinar. Éste ha de ser concebido como el percatarse de la unilateralidad de las perspectivas particulares, la toma de conciencia de su carácter limitado y de la posibilidad de ponerlas en armonía, gracias a ciertas posibilidades de "intertraducción”, a la existencia de interconexiones, de homologías y analogías. Todo esto aumenta el grado de comprensión del objeto de estudio, que nunca llega a ser completamente cumplido, sólo razonablemente alcanzado, si se cumple con el logro de los objetivos trazados.

Lo anterior conduce a afirmar que la interdisciplinariedad orientada por una hermenéutica de carácter analógico retoma, dentro de un orden de proporción y atribución, el carácter de interdependencia e interacción que existe entre las realidades y las ideas; rescata su visión de contexto y hace tangible una red de interacciones donde se 
conectan los conceptos y las teorías. Además, contribuye a entender que las personas no aprenden exclusivamente con el uso de la razón o el intelecto, sino que en este proceso de construcción, la intuición, las sensaciones, las emociones y los sentimientos cumplen un papel fundamental. Es un movimiento que cree en la creatividad de las personas, en la complementariedad de los procesos, en la integridad de las relaciones, en el diálogo, en la problematización, en la actitud crítica y reflexiva; en fin, en una visión articuladora que rompe con el pensamiento disciplinar, fragmentado, jerárquico, dualista, dogmático y equivocista.

\section{Siete tesis que plantean una propuesta}

A manera de conclusión, se plantean siete tesis que aportan a la configuración de un modelo analógico de comprensión de textos:

1. La interdisciplinariedad propuesta por Agazzi y Beuchot se enmarca en un sistema de comprensión de la realidad que no se limita a la transferencia de métodos de una disciplina a otra, sino que traza puentes que relacionan los núcleos de referencia y de sentido para solucionar muchos de los problemas sociales contemporáneos.

2. Esta comprensión analógica de la realidad social requiere establecer relaciones y aplicaciones que vayan más allá de los métodos utilizados por las disciplinas inmersas en las ciencias sociales. Para tal fin es necesario construir una fundamentación ontológica y epistemológica de estas ciencias a la luz de una profundización de los elementos y efectos de la hermenéutica analógica.

3. Este modelo de interpretación ofrece elementos claros de diferenciación y complementariedad del carácter semántico, sintáctico y paradigmático de la comprensión lectora, que han de balancear la dinámica del argumento (en tanto uso de la inducción, abducción y deducción) con la múltiple variación del ícono (en tanto imagen, diagrama y metáfora). 
4. Pierpaolo Donati $(2006 ; 2010)$ propone un giro relacional en la sociología, que invita a pensar por relaciones, a comprender y explicar en relaciones, en donde lo social no se centra en el individuo o en el sistema, sino en la relación social como referencia significativa. Este giro relacional es armónico con los elementos constitutivos de la hermenéutica analógica y resulta vital para la comprensión de cuestiones interdisciplinares que impliquen desarrollos sociológicos.

5. Es necesario descentrar la comprensión de textos del ámbito de la educación formal y plantear un modelo en el ámbito de la educación no formal que haga uso del concepto de formación rescatado por Beuchot, y que apunte a un concepto de formación permanente, como proceso constante a lo largo de la vida, que coadyuve al desarrollo de criterios capaces de vincular teoría y praxis, textos y contextos, a la luz de un experienciar la cotidianidad.

6. El modelo de comprensión de textos propuesto por Marciales (2003: 92-136), que relaciona los factores textuales, contextuales, subjetivos e intersubjetivos, los cuales giran alrededor de los ejes procesual, interactivo, constructivo y mediacional, son muy útiles para desarrollar un nuevo modelo de carácter interdisciplinar, enfocado ya no desde la perspectiva constructivista, sino desde la hermenéutica analógica.

7. La relación que explora Beuchot (2011a: 85-87) entre la visión de modelos, metáforas y analogía, es fundante para la construcción de un modelo formativo en comprensión lectora.

\section{Bibliografía}

AgAzzi, Evandro (2002). "El desafío de la interdisciplinariedad: dificultades y logros", Revista Empresa y Humanismo, 5 (2): 241-252.

Alonso, J. y M. Mateos (1985). "Comprensión lectora: modelos, entrenamiento y evaluación", Infancia y Aprendizaje, 31-32: 5-19.

BECHER, Tony (2001). Tribus y territorios académicos. La indagación intelectual y las culturas de las disciplinas. Barcelona, Gedisa.

Beuchot, Mauricio (1999). Las caras del símbolo: el ícono y el ídolo. Madrid, Caparrós. 
Beuchot, Mauricio (2007). Phrónesis, analogía y hermenéutica. México, Universidad Nacional Autónoma de México.

- (2009a). Tratado de hermenéutica analógica. Hacia un nuevo modelo de interpretación. México, Universidad Nacional Autónoma de México, FFYL/Ítaca.

- (2009b). Hermenéutica analógica y educación multicultural. México, Universidad Nacional Autónoma de México, FFYL/Ítaca.

- (2010a). Hermenéutica analógica, símbolo y ontología. México, Universidad Autónoma del Estado de México.

- (2010b). Hermenéutica analógica y búsqueda de la comprensión. México, Universidad Autónoma de Chihuahua, Colección Textos Universitarios.

- (2011a). Epistemología y hermenéutica analógica. México, Universitaria Potosina/Instituto de Investigaciones Humanísticas de la Universidad Autónoma de San Luis Potosí.

- (2011b). "Sobre la analogía y la filosofía actual”, en A. Herrera Ibáñez (comp.), Metáfora y analogía. México, Torres Asociados: 149-168.

Cole, Michel (1996). Cultural psychology, A once and future discipline. Cambridge, Harvard University Press.

Coll, Cesar (2001). "Constructivismo y educación: la concepción constructivista de la enseñanza y el aprendizaje”, en C. Coll, J. Palacios y A. Marchesi (comps.), Psicología de la educación escolar. Madrid, Alianza: 157-177.

Conesa, Francisco y Jaime Nubiola (1999). Filosofía del lenguaje. Barcelona, Herder.

CoReth, Emerich (1972). Cuestiones fundamentales de hermenéutica. Barcelona, Herder.

De VEGA, Manuel (1994). Introducción a la psicología cognitiva. Madrid, Alianza Editorial.

Donati, P. (2006). Repensar la sociedad. Madrid, Ediciones Internacionales Universitarias.

- (2010). Relational sociology. A new paradigm for the social sciences. London, Routledge.

ElmborG, James (2008). “Alfabetización informacional crítica: implicaciones para la práctica educativa", Boletín de la Asociación Andaluza de Bibliotecarios, 92-93:103-121.

FreIRE, P. y Donaldo MACEDo (1989). Alfabetización: lectura de la palabra y lectura de la realidad. Barcelona, Paidós.

GERnSBACHER, Morton (1990). Language comprehension as structure building. Hillsdale, Erlbaum.

- (1991). "Cognitive processes and mechanisms in language comprehension: the structure building framework", en G. H. Bower (ed.), The psychology of learning and motivation. New York, Academic Press: 217263.

- (1996). "The structure-building framework: What it is, what it might 
also be, and why”, en B.K. Britton y A.C. Graesser (eds.), Models of understanding text. Mahwah, Lawrence Erbaum.

Gernsbacher, Morton (1997). "Two decades of structure building”, Discourse Processes, 23: 265-304.

Goodman, Kenneth (1984). "El proceso de lectura: consideraciones a través de las lenguas y del desarrollo", en E. Ferreiro y P. Gómez, Nuevas perspectivas sobre los procesos de lectura y escritura. México, Siglo XXI: $13-28$.

InCIARTE, F. y A. Llano (2007). Metafísica tras el final de la metafísica. Madrid, Ediciones Cristiandad.

JAPIASSU, Hilton (1976). Interdisciplinaridade e patologia do saber. Rio de Janeiro, Imago.

Just, M. A. y P. CARPENTER (1980). "A theory of reading: From eye fixations to comprension”, Psychological Review, 87 (4): 329-354.

- (1992). "A capacity theory of comprehension: Individual differences in working memory", Psychological Review, 99: 122-149.

Just, M. A., P. Carpenter y J. D. Wooley (1982). "Paradigms and processes in text comprehension", Journal of Experimental Psychology: General, 111: 228-238.

KINTSCH, Walter (1980). "Learning from text, levels of comprehension, or: Why anyone would read a story anyway", Poetics, 9: 87-98.

- (1988). "The use of knowledge in discourse processing: A construction-integration model", Psychological Review, 95: 163-182.

- (1998). Comprehension. A paradigm for cognition. Cambridge, Cambridge University Press.

Llano, Alejandro (1997). Metafísica y lenguaje. Pamplona, Ediciones Universidad de Navarra.

- (1999). Humanismo cívico. Barcelona, Ariel.

Marciales, Gloria Patricia (2003). "Pensamiento crítico: diferencias en estudiantes universitarios en el tipo de creencias, estrategias e inferencias en la lectura crítica de textos". Tesis (doctorado), Facultad de Educación de la Universidad Complutense de Madrid. Madrid, España.

Melich, Joan Carles (1994). Del extraño al cómplice: la educación en la vida cotidiana. Barcelona, Anthropos.

Morin, Edgar (2005). Educação e complexidade, os sete saberes e outros ensaios. Sao Paulo, Cortez.

Nussbaum, Martha (2010). Sin fines de lucro: Por qué la democracia necesita de las humanidades. Buenos Aires, Katz Editores.

PeÑA, Luis Bernardo y Beatriz Helena IsAZA (2005). Una región de lectores. Bogotá, Ilímita.

Ricoeur, Paul (2002). Del texto a la acción ensayos de hermenéutica II. México, Fondo de Cultura Económica.

Ripoll, Juan Carlos (2010). "La concepción simple de la lectura en educación primaria: una revisión sistemática". Tesis (doctorado), Facultad de Filosofía y Letras de la Universidad Navarra. Pamplona, España. 
Robledo, Beatriz (2010). El arte de la mediación: espacios y estrategias para la promoción de lectura. Bogotá, Norma.

Rodríguez, Gloria (2007). "La biblioteca pública en Colombia: miradas de una realidad”. Congreso Internacional La biblioteca pública: un continente entre los continentes. Medellín, noviembre de 2007.

RuIz, L. E. (2010). "Biblioteca Nacional de Colombia", <http://www.bibliotecanacional.gov.co/recursos_user/BibliotecasPublicas/presentacion proyecto Interculturalidad y biblioteca publica al II Congreso Nal de bibliotecas publicas.pdf>, consultado por última vez el 15 de agosto de 2011.

Santiuste Bermejo, Víctor (2001). "Quelques réflexions sur la valur éducative de la philosophie", Conferencia presentada en las Escuelas Europeas. Bruselas, Seminario de Filosofía.

SMAGORINSKY, Peter (2001). "If meaning is constructed, what is it made from? Toward a cultural theory of reading", Review of Educational Research, 71 (1): 133-169.

SolÉ, Isabel (1992). Estrategias de lectura. Barcelona, Grao.

- y A. Teberosky (2001). "La enseñanza y el aprendizaje de la alfabetización: una perspectiva psicológica", en J. PALACIOS, A. MARCHESSY y C. Coll (comps.), Desarrollo psicológico y educación. Madrid, Alianza: 461-485.

ZwaAn, Rolf A., Mark C. Langston y Arthur C. Graesser (1995). "The construction of situation models in narrative comprehension: An Event-Indexing Model”, Psychological Science, vol. 6, núm. 5: 292297.

- y Gabriel A. RADVASNKY (1998). "Situation models in language comprehension and memory", Psychological Bulletin, vol. 123, núm. 2: 162-185.

- (2004). "The immersed experiencer: toward an embodied theory of language comprehension", en B. H. Ross (ed.), The psychology of learning and motivation. New York, Academic Press: 35-62. 
